\title{
Selenium intake and nutritional status of children with phenylketonuria in Minas Gerais, Brazil
}

\author{
Michelle R. A. Alves, ${ }^{1}$ Ana L. P. Starling, ${ }^{2}$ Viviane C. Kanufre, ${ }^{3}$ Rosângelis D. L. Soares, ${ }^{4}$ \\ Rocksane de C. Norton, ${ }^{5}$ Marcos J. B. Aguiar, ${ }^{6}$ José N. Januario $^{7}$
}

\begin{abstract}
Objective: To evaluate selenium dietary intake and nutritional status of patients with phenylketonuria.

Methods: The study prospectively evaluated 54 children with phenylketonuria, from 4 to 10 years old. The study was performed before and after the use of a selenium-supplemented amino acid mixture. The second phase of the study was performed after, at least, 90 days of use of the supplementation. Selenium nutritional status was assessed through the analysis of biochemical parameters: serum free thyroxin and selenium and glutathione peroxidase in erythrocytes. Selenium dietary intake was evaluated by the administration of the Food Frequency Questionnaire.

Results: Mean age of the children was of $7.0 \pm 1.8$ years, and $35.2 \%$ were female. Mean time of supplementation of selenium, on special formula, was $122.2 \pm 25.1$ days. The selenium-supplemented amino acid mixture represented $72.9 \%$ of the daily supply of the mineral. Upon supplementation, mean concentrations of serum selenium and glutathione peroxidase in erythrocytes increased significantly $(p<0.05)$. The average daily intake of selenium increased significantly $(p<0.001)$, reaching the levels recommended by the Dietary Reference Intakes. The concentration of free thyroxin, in serum, presented significant reduction $(p<0.001)$ in all patients during the second phase of the study, and returned to normal limits in those who had changed levels.

Conclusion: Selenium supplementation through protein replacement is effective to improve and adapt the nutritional status of selenium in patients with phenylketonuria.

J Pediatr (Rio J). 2012;88(5):396-400: Phenylketonuria, selenium, glutathione peroxidase, thyroid hormones.
\end{abstract}

\section{Introduction}

Phenylketonuria (PKU) is an autosomal recessive disorder characterized by the absence or deficiency of the enzyme phenylalanine hydroxylase, which prevents the hydroxylation of phenylalanine (phe) to tyrosine (Tyr). Consequently, there is an increase of phe in the blood, causing changes in the central nervous system and irreversible mental retardation, among other manifestations. ${ }^{1}$

Treatment of PKU is accomplished through the use of phe-restricted diet, with significant reduction in the ingestion of natural proteins. To complete the daily requirement of

1. MSc, Saúde da Criança e do Adolescente. Nutritionist, Núcleo de Ações e Pesquisa em Apoio Diagnóstico (NUPAD), Faculdade de Medicina (FM), Universidade Federal de Minas Gerais (UFMG), Belo Horizonte, MG, Brazil. Adjunct professor, Faculdade de Nutrição, Pontifícia Universidade Católica de Minas Gerais (PUCMinas), Belo Horizonte, MG, Brazil.

2. PhD, Saúde da Criança e do Adolescente. Adjunct professor, Departamento de Pediatria, FM, UFMG, Belo Horizonte, MG, Brazil. Associate investigator, Academic director, NUPAD, FM, UFMG, Belo Horizonte, MG, Brazil.

3. MSc, Saúde da Criança e do Adolescente. Clinical nutritionist, Serviço de Nutrição, Hospital das Clínicas, UFMG, Belo Horizonte, MG, Brazil. Nutritionist, NUPAD, FM, UFMG, Belo Horizonte, MG, Brazil.

4. PhD candidate, Saúde da Criança e do Adolescente. Clinical nutritionist, Serviço de Nutrição, Hospital das Clínicas, UFMG, Belo Horizonte, MG, Brazil. Nutritionist, NUPAD, FM, UFMG, Belo Horizonte, MG, Brazil.

5. PhD, Gastroenterologia. Nutrologist physician, Sociedade Brasileira de Pediatria. Associate professor, Departamento de Pediatria, FM, UFMG, Belo Horizonte, MG, Brazil. Associate investigator, NUPAD, FM, UFMG, Belo Horizonte, MG, Brazil.

6. PhD, Pediatria. Associate professor, Departamento de Pediatria, FM, UFMG, Belo Horizonte, MG, Brazil. Geneticist, Associate investigator, Vice Director, NUPAD, FM, UFMG, Belo Horizonte, MG, Brazil.

7. MSc, Saúde da Criança e do Adolescente. Assistant professor, Departamento de Clínica Médica, FM, UFMG, Belo Horizonte, MG, Brazil. Director, Associate investigator, NUPAD, FM, UFMG, Belo Horizonte, MG, Brazil.

No conflicts of interest declared concerning the publication of this article.

Suggested citation: Alves MR, Starling AL, Kanufre VC, Soares RD, Norton RC, Aguiar MJ, et al. Selenium intake and nutritional status of children with phenylketonuria in Minas Gerais, Brazil. J Pediatr (Rio J). 2012;88(5):396-400.

Manuscript submitted Nov 22 2011, accepted for publication May 302012.

http://dx.doi.org/10.2223/JPED.2217 
protein in the diet, a substitute for protein is provided protein hydrolysate or amino acid mixture - free of or with low concentrations of phe, added by Tyr, vitamins and minerals ${ }^{2}$; many of them, however, with no selenium supplementation.

Studies have reported a deficiency of selenium in patients with PKU who use this type of product, concluding that supplementation was needed, not only due to the small quantity contained in food ingested by these patients, but also for a possible low bioavailability of the nutrient. ${ }^{3}$ The main sources of selenium are foods rich in protein of high biological value, such as meat, eggs, milk, cereals and oilseeds, which are prohibited for patients with PKU.4,5 Vegetables, which are the only natural protein sources for people with $\mathrm{PKU}$, have, in general, concentrations lower than $5 \mathrm{mcg} / 100 \mathrm{~g} .5$

Supplementation is recommended either through the use of a specific product or through the addition of selenium in the protein substitute, or even through the use of foods rich in selenium. ${ }^{6}$

Selenium is a cofactor of glutathione peroxidase (GPX), fundamental for the antioxidant system, and is involved in the synthesis of the iodothyronine $5^{\prime}$-deiodinase (selenoenzyme). ${ }^{6}$ The low intake of this mineral alters the thyroid function, decreasing serum concentrations of triiodothyronine (T3) and increasing simultaneously, the concentrations of free thyroxine (FT4). ${ }^{7}$ Therefore, the decrease in the concentration of selenium is accompanied by an increase in FT4 by reducing the activity of the iodothyronine 5 '-deiodinase enzyme.

An inadequate intake and low levels of selenium in the blood, in the long run, were related to the Keshan syndrome, characterized by cardiomyopathy and various degrees of cardiac hypertrophy, and the Kashin-Beck disease, characterized by endemic osteoarthritis presented by necrotic degeneration of chondrocytes, symmetric stiffness and pain in the interphalangeal joints of the hands, followed by a generalized osteoarthritis, dwarfism, and joint deformations as final results. However, the dietary or supplement use of selenium does not reverse the clinical scenarios once installed. These syndromes were described in some regions of China. 8,9 Signs and symptoms related to biochemical deficiency of this mineral, in PKU patients, have not been described in other countries. ${ }^{7,10}$

This study aimed to assess the nutritional status of selenium in patients with PKU, aged between 4 and 10 years, with early diagnosis and treatment, treated by the Special Genetics Service at Hospital das Clínicas within Universidade Federal de Minas Gerais (UFMG). The efficiency of using a selenium-supplemented amino acid mixture in the recovery of possible mineral deficiencies was also verified, guaranteeing, thus, a more appropriate treatment for the patients.

\section{Methods}

We conducted a prospective cohort study with 54 patients with PKU, from 4-10 years old, early diagnosed and treated. The study was divided in two phases: the first, or phase 1, happened before the child ingested selenium-supplemented amino acid mixture; the second, or phase 2, happened at least 90 days after the onset of consumption of the mixture supplemented with the mineral.

The assessment of dietary intake of selenium was performed by Quantitative Food Frequency Questionnaire (QFFQ) adapted for people with PKU. The preparation of the list of foods present in the QFFQ was based on 24 or 72hour dietary recalls, obtained from each child's nutritional records. The parent or guardian, answered the QFFQ on the day of the consultation, through an interview. The calculation of selenium content in foods was analyzed by the Diet Pro ${ }^{\circledR} 4.0$ software.

The selenium content of most foods was obtained from the tables contained in the Brazilian study of Ferreira et al. ${ }^{5}$ and the table from the Department of Agriculture in the United States. ${ }^{11}$ Dietary intake of selenium was compared to the Dietary Reference Intake/Recommended Dietary Allowances (DRI/RDA).

The selenium content of the selenium-supplemented amino acid mixture has been removed from the label of the product used by patients. Children were divided according to age group, so that the intake of selenium, according to the recommendation of DRI/RDA, could be assessed.12

In the first phase of the study, the intake of selenium indicated only to the content of selenium on the diet of the patient, once the mixture of amino acids was not supplemented. In the second phase, the amount of selenium indicated the content of selenium on the diet plus the content of the selenium-supplemented amino acid mixture.

To perform the biochemical tests, we collected from each child: $3.0 \mathrm{~mL}$ whole blood in dry tube to obtain serum for measurement of free $\mathrm{T} 4 ; 4.0 \mathrm{~mL}$ of whole blood in heparin tube for determination of GPX in erythrocytes; $6.0 \mathrm{~mL}$ of whole blood in a trace tube (special tube, metal free) for measurement of serum selenium. The measurement of serum selenium were made by atomic absorption spectrophotometry (reference value $[\mathrm{RV}]=46.0-143.0$ $\mathrm{mcg} / \mathrm{L})^{13}$; the measurement of GPX, in erythrocytes by an enzymatic method ( $R V=27.5-73.6 \mathrm{U} / \mathrm{G} \mathrm{Hb}$ ) (Randox Laboratories, Antrim, UK); and the measurements of FT4, by chemiluminescence ( $R V=0.54-1.24$ nanog/dL) (Unicel DxI $800^{\circledR}$, Beckman Coulter, Brea, EUA).

Data were analyzed with the Statistical Package for the Social Sciences 10.0. Categorical variables were analyzed as simple frequencies and percentages. Quantitative variables were evaluated by calculation of means, medians, and standard deviations. To study the association between continuous variables, we used the 
Pearson ( $r$ ) correlation test. The chi-square test was used to study the association between categorical variables. To compare means, we used Student's $t$ test. Statistically significance was established at $p<0.05$. The McNemar test was used to assess whether the children were able to reach the reference ranges of biochemical tests, establishing $p \leq 0.05$ as statistically significant.

The parents signed an informed consent form, authorizing the child to take part in the study, which was approved by the Research Ethics Committee of the University, under n. ETIC 468/06.

\section{Results}

Among the 54 children, 19 (35.2\%) were female, 43 (79.6\%) were between 4 and 8 years old, and 11 (20.4\%) were between 9 and 10 years, with mean age of $7.0 \pm 1.8$ years. The mean time of use of the supplemented amino acid mixture was of $122.2 \pm 25.1$ days.

A high percentage $(67.9 \%)$ of GPX below the values of reference was found in the first phase, while in the second phase, after the complementation, only $18.5 \%$ remained with values below the recommended $(p<0.001)$.

Regarding serum selenium, it was observed that $98.1 \%$ of patients presented values below the recommendation in the first phase, and after the supplementation, $18.5 \%$ reached adequate concentrations. There was, however, a statistically significant increase in the content of serum selenium, in all patients, when the two phases of the study were compared $(p=0.0016)$.

In the first phase, $16.7 \%(n=9)$ of patients had FT4 above the recommended value. After the supplementation with the mineral, values of FT4, in these cases, reached normal values. It was also observed a reduction in the level of the hormone in all patients in the second phase of the study ( $p=0.004)$.
The mean serum concentrations of GPX, selenium and FT4, in the two studied phases, are demonstrated in Table 1 . It is observed that there was a statistically significant difference, between the two phases in all parameters assessed.

Only with natural food consumption, there was an average intake of selenium far below the recommended levels. Table 2 presents the mean of selenium content (mcg/day) supplied by a normal diet (phase 1 ) and by adding the mixture of amino acids supplemented with selenium (phase 2 ) in both age groups. There was a statistically significant increase in the supply of selenium between the two phases.

The selenium-supplemented amino acid mixture accounted for $72.9 \%$ of the total dietary offer of the micronutrient. Figure 1 shows the contribution of the amino

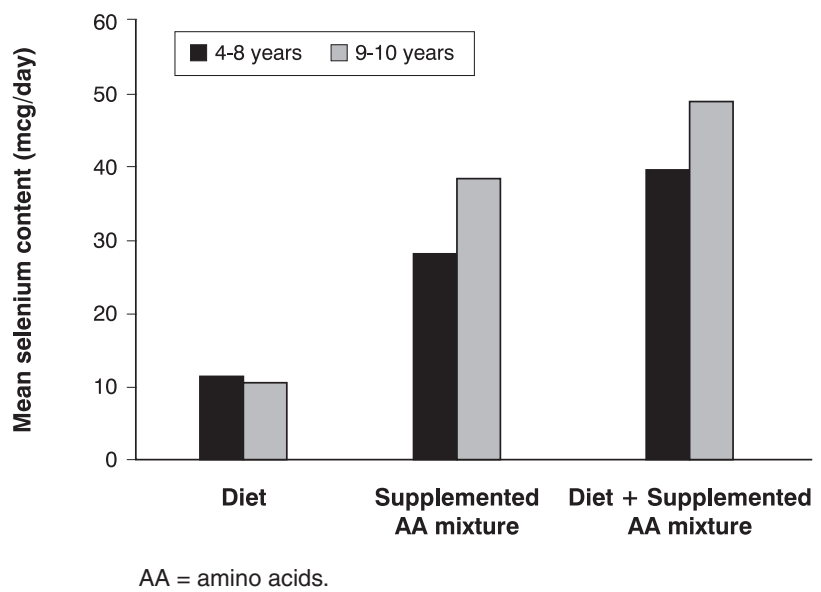

Figure 1 - Contribution of the amino acid mixture in relation to the mean selenium content ( $\mathrm{mcg} / \mathrm{day}$ ) in the diet of 54 children with phenylketonuria, in the age groups studied

Table 1 - Mean and standard deviation of the concentrations of glutathione peroxidase, serum selenium and free thyroxine of 54 children with phenylketonuria, between 4 and 10 years old, before and after the use of selenium-supplemented amino acid mixture

\begin{tabular}{|c|c|c|c|c|}
\hline Concentrations & $\begin{array}{c}\text { Phase } 1 \\
\text { Mean } \pm \text { SD }\end{array}$ & $\begin{array}{c}\text { Phase } 2 \\
\text { Mean } \pm \text { SD }\end{array}$ & $\mathbf{p}$ & McNemar test \\
\hline $\mathrm{GPX}(\mathrm{U} / \mathrm{G} \mathrm{Hb})$ & $23.92 \pm 10.12$ & $40.93 \pm 12.84$ & $0.015^{*}$ & $<0.001^{*}$ \\
\hline Selenium (mcg/L) & $13.19 \pm 12.67$ & $31.39 \pm 15.79$ & $0.009 *$ & $0.016 *$ \\
\hline FT4 (nanog/dL) & $1.05 \pm 0.2$ & $0.91 \pm 0.12$ & $<0.001 *$ & $0.004^{*}$ \\
\hline
\end{tabular}

FT4 = free thyroxine; GPX = glutathione peroxidase; SD = standard deviation.

* Statistical significance. 
Table 2 - Means of selenium micrograms per day ( $\mathrm{mcg} / \mathrm{day}$ ) provided by normal diet and by the mixture of amino acids, according to the age groups analyzed

\begin{tabular}{|c|c|c|c|c|c|}
\hline Age group & $\begin{array}{c}\text { Phase } 1 \\
\text { Diet }\end{array}$ & $\begin{array}{c}\text { Phase } 2 \\
\text { Mixture of AA* }\end{array}$ & $\begin{array}{c}\text { Diet }+ \\
\text { Mixture of AA* }\end{array}$ & DRI/RDA & $\mathbf{p}$ \\
\hline $4-8$ years $(n=43)$ & $11.5 \pm 6.7$ & $28.3 \pm 6.2$ & $39.8 \pm 8.8$ & 30 & $<0.001^{+}$ \\
\hline $9-10$ years $(n=11)$ & $10.7 \pm 4.7$ & $38.4 \pm 9.2$ & $49.1 \pm 11.6$ & 40 & $0.026^{+}$ \\
\hline
\end{tabular}

$\mathrm{AA}=$ amino acids; DRI/RDA = Dietary Reference Intakes/Recommended Dietary Allowances.

* Mixture of amino acids supplemented with selenium.

† Statistical significance.

acid mixture compared to the average content of selenium (mcg/day) in the diet of 54 children with PKU, in the age groups studied, before and after supplementation.

There were no clinical signs and symptoms related to selenium deficiency.

\section{Discussion}

The number of children with PKU participating in this study ( $n=54$ ) should be emphasized, because as far as it is known, it is the largest sample of patients with PKU coming from the same referral center for treatment of the disease, in which the nutritional status of selenium was studied. This number represents $67 \%$ of patients, aged between 4 and 10 years, and 30\% of all those with PKU diagnosed and treated early in the state of Minas Gerais, since 1993, when the program was implemented. It is important to know that the early treatment, in a study conducted in the same reference center, prevented mental retardation in $90.5 \%$ of patients. ${ }^{14}$ It is, therefore, a fairly representative sample of this population. Furthermore, the use of the same patients as controls, in both phases of the study, reduced the bias of the interindividual comparison.

Some studies with phenylketonuric children found significant reduction in the GPX activity in the erythrocyte, plasma and erythrocyte-selenium concentrations and increased oxidative stress related to the low intake of the micronutrient compared to controls. Supplementation of selenium, in the diet, normalized the concentrations of all biochemical parameters related to the mineral, 15,16 as found in the present study.

As the protein substitute is obtained by a bidding, it was not possible to increase the time of use of the seleniumsupplemented mixture, due to change for a new product. Studies report that 90 days are enough for selenium serum concentrations, as well as concentrations of GPX in the erythrocyte, to increase and even reach normal levels. ${ }^{16}$ While there has been significant increase in the content of selenium and GPX in erythrocytes, as well as significant decrease in FT4, serum concentrations of selenium have not reached the normal range in most patients in this study. Perhaps a longer time of supplementation would be required. However, we found that this supplementation was sufficient to reverse or improve, significantly, the nutritional status of selenium in most children.

This is the only Brazilian study evaluating the thyroid hormone (FT4) from the point of view of selenium deficiency, besides being the only Brazilian study assessing the supplementation of selenium in children under treatment for PKU. Concentrations of FT4 above the reference values were found in some patients, which may be explained by a decrease in the activity of the enzyme $5^{\prime}$ iodothyronine deiodinase, due to reduced concentrations of selenium in the body. ${ }^{17-19}$ After supplementation with selenium, concentrations of FT4 in these patients, as well as in the whole group, reduced significantly, remaining within an appropriate range, which may be explained by the greater availability of selenium, resulting from the standardization of intake, similar to what was verified in other studies.7,19

The low consumption of selenium, by patients with PKU, was also reported in reviews by other authors. 20,21 In one of the studies, it was observed selenium deficiency even with its presence in the composition of the protein substitute. ${ }^{21}$ The mixture of amino acids was the main source of selenium for the patients studied.

Using the content of selenium of foods from the Brazilian study ${ }^{5}$ reduced the bias that could have been produced by the use of foods from composition tables of other countries. Although the food in this study was not primarily grown in the states of Minas Gerais, many samples were collected from products in the state, but all were produced in Brazil. 
One of the positive aspects of this study is the supplementation of selenium by adding it to the amino acid mixture, ensuring access to the mineral for all patients, from all age groups. It also avoids inadequate handling and problems in acquisition/purchase of the substance used as a complement, avoiding errors in the calculation of the dose to be used. The increase of the biochemical parameters related to selenium supplementation increases the need for solid mineral, justified by the existence of a positive correlation between serum selenium concentrations and dosages of GPX in erythrocytes. ${ }^{22}$

As reported in the literature, $16,22,23$ no clinical manifestations of selenium deficiency were found in our patients. Therefore, selenium deficiency in this population is only biochemical. Since the public system does not provide access to these diagnostic exams, it is not possible to obtain, routinely, an assessment of the nutritional state of selenium in all patients. The literature is unanimous in highlighting the need for selenium supplementation in patients with phenylketonuria, once subclinical manifestations may happen, such as changes in myocardial function observed in echocardiograms of children with PKU. ${ }^{24}$

The selenium supplementation in patients with PKU should be recommended, therefore, preferably through the continuous use of protein substitutes supplemented with selenium in all age groups. A thorough investigation of the intake should be performed, as well as an assessment of the biochemical markers of selenium levels in the body, whenever possible, to avoid further damage to health, caused by deficiency of this nutrient.

\section{References}

1. Scriver $C R$, Kaufman $S$. Hyperphenylalaninemia: phenylalanine hydroxylase deficiency. In: Scriver CR, Beaudet AL, Sly WS, Valle $D$, Childs B, Vogelstein B, eds. The metabolic and molecular basis of inherited disease. 8th ed. New York: McGraw-Hill; 2001. p. 1667-724.

2. Acosta PB, Yanniccelli S. The Ross metabolic formula system, nutrition support protocols. 4th ed. Columbus: Ross Laboratories, Library of Congress; 2001. 432p.

3. Mira NV, Marquez UM. Importance of the diagnoses and treatment of phenylketonuria. Rev Saude Publica. 2000;34:86-96.

4. Kanufre VC, Santos JS, Soares RD, Starling AL, Aguiar MJ. Abordagem dietética para fenilcetonúria. Rev Med Minas Gerais. 2001;11:129-34.

5. Ferreira KS, Gomes JC, Bellato CR, Jordão CP. Selenium concentration in food consumed in Brazil. Rev Panam Salud Publica. 2002;11:172-7.

6. Rayman MP. The importance of selenium to human health. Lancet. 2000;356:233-41.

7. Köhrle J. Selenium and the control of thyroid hormone metabolism. Thyroid. 2005;15:841-53.

8. Food and Agriculture Organization of the United Nations (FAO), World Health Organization (WHO). Vitamin and mineral requirements in human nutrition. 2nd ed. Geneva: World Health Organization. 2004.
9. Brenneisen $\mathrm{P}$, Steinbrenner $\mathrm{H}$, Sies $\mathrm{H}$. Selenium, oxidative stress, and health aspects. Mol Aspects Med. 2005;26:256-67.

10. Jochum F, Terwolbeck K, Meinhold H, Behne D, Menzel H, Lombeck I. Is there any health risk of low dietary selenium supply in PKU children? Nutr Res. 1999;19:349-60.

11. U.S. Department of Agriculture, Agricultural Research Service. 2011. USDA National Nutrient Database for Standard Reference, Release 24. https://www.ars.usda.gov/SP2UserFiles/ Place/12354500/Data/SR24/nutrlist/sr24w317.pdf. Access: 03/05/2011.

12. Food and Nutrition Board, Institute of Medicine, National Academies. Dietary Reference Intakes (DRIs): Recommended Dietary Allowances and Adequate Intakes, Vitamins. http://iom.edu/ Activities/Nutrition/SummaryDRIs/ /media/Files/Activity $\% 20$ Files/Nutrition/DRIs/RDA\%20and\%20AIs_Vitamin\%20and\%20 Elements.pdf. Access: 28/04/2011.

13. Iyengar $\mathrm{V}$, Woittiez J. Trace elements in human clinical specimens: evaluation of literature data to identify reference values. Clin Chem. 1988;34:474-81.

14. Castro IP, Borges JM, Chagas HA, Tibúrcio J, Starling AL, de Aguiar MJ. Relationships between phenylalanine levels, intelligence and socioeconomic status of patients with phenylketonuria. J Pediatr (Rio J). 2012 Mar 28. [Epub ahead of print]

15. Sitta A, Barschak AG, Deon M, Terroso T, Pires R, Giugliani R, et al. Investigation of oxidative stress parameters in treated phenylketonuric patients. Metab Brain Dis. 2006;21:287-96.

16. Wilke BC, Vidailhet M, Favier A, Guillemin C, Ducros V, Arnaud $\mathrm{J}$, et al. Selenium, glutathione peroxidase (GSH-Px) and lipid peroxidation products before and after selenium supplementation. Clin Chim Acta. 1992;207:137-42.

17. Arthur JR, Beckett GJ. Thyroid function. Br Med Bull. 1999;55:658-68

18. Lombeck I, Jochum F, Terwolbeck K. Selenium status in infants and children with phenylketonuria and in maternal phenylketonuria. Eur J Pediatr. 1996;155:S140-4.

19. Zimmermann MB, Köhrle J. The impact of iron and selenium deficiencies on iodine and thyroid metabolism: biochemistry and relevance to public health. Thyroid. 2002;12:867-78.

20. Reilly C, Barrett JE, Patterson CM, Tinggi U, Latham SL, Marrinan A. Trace element nutrition status and dietary intake of children with phenylketonuria. Am J Clin Nutr. 1990;52:159-65.

21. Dobbelaere D, Michaud L, Debrabander A, Vanderbecken S, Gottrand F, Turck D, et al. Evaluation of nutritional status and pathophysiology of growth retardation in patients with phenylketonuria. J Inherit Metab Dis. 2003;26:1-11.

22. Artuch R, Colomé C, Sierra C, Brandi N, Lambruschini N, Campistol $\mathrm{J}$, et al. A longitudinal study of antioxidant status in phenylketonuric patients. Clin Biochem. 2004;37:198-203.

23. Barretto JR, Silva LR, Leite ME, Boa-Sorte N, Pimentel H, Purificação $\mathrm{AC}$, et al. Poor zinc and selenium status in phenylketonuric children and adolescents in Brazil. Nutr Res. 2008;28:208-11.

24. Gordon SJ, Latham SC, Spink JD, Galbraith AJ. Assessment of cardiac function by M-mode echocardiography in seleniumdeficient phenylketonuric children. J Paediatr Child Health. $1991 ; 27: 47-50$.

Correspondence:

Michelle Rosa Andrade Alves

Rua Diametral, 116/13, bloco A, Sagrada Família

CEP 31030-350 - Belo Horizonte, MG - Brazil

Tel. : +55 (31) 3457.1382, +55 (31) 9663.1288

E-mail: michellenutric@hotmail.com 